\title{
Policy brief: Fertility preferences and behaviors among younger cohorts in Egypt: Recent trends, correlates, and prospects for change [Arabic]
}

Nahla G. Abdel-Tawab

Population Council

Shadia Attia

Nourhan Bader

Rania Roushdy

Shatha El-Nakib

See next page for additional authors

Follow this and additional works at: https://knowledgecommons.popcouncil.org/departments_sbsr-rh

Part of the Demography, Population, and Ecology Commons, Family, Life Course, and Society

Commons, and the International Public Health Commons

How does access to this work benefit you? Let us know!

\section{Recommended Citation}

Abdel-Tawab, Nahla G., Shadia Attia, Nourhan Bader, Rania Roushdy, Shatha El-Nakib, and Doaa Oraby. 2020. "Policy brief: Fertility preferences and behaviors among younger cohorts in Egypt: Recent trends, correlates, and prospects for change," Policy brief in Arabic. Washington, DC: Population Council, The Evidence Project. 
Authors

Nahla G. Abdel-Tawab, Shadia Attia, Nourhan Bader, Rania Roushdy, Shatha El-Nakib, and Doaa Oraby 


\section{نظرة تلى تهضيلات وسلوكيات الإنجاب بين

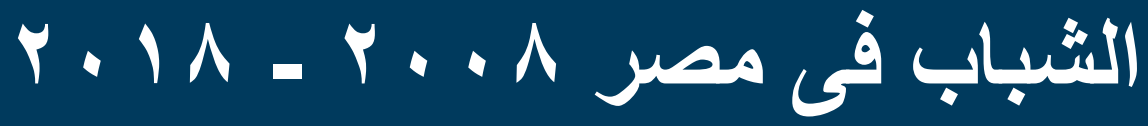

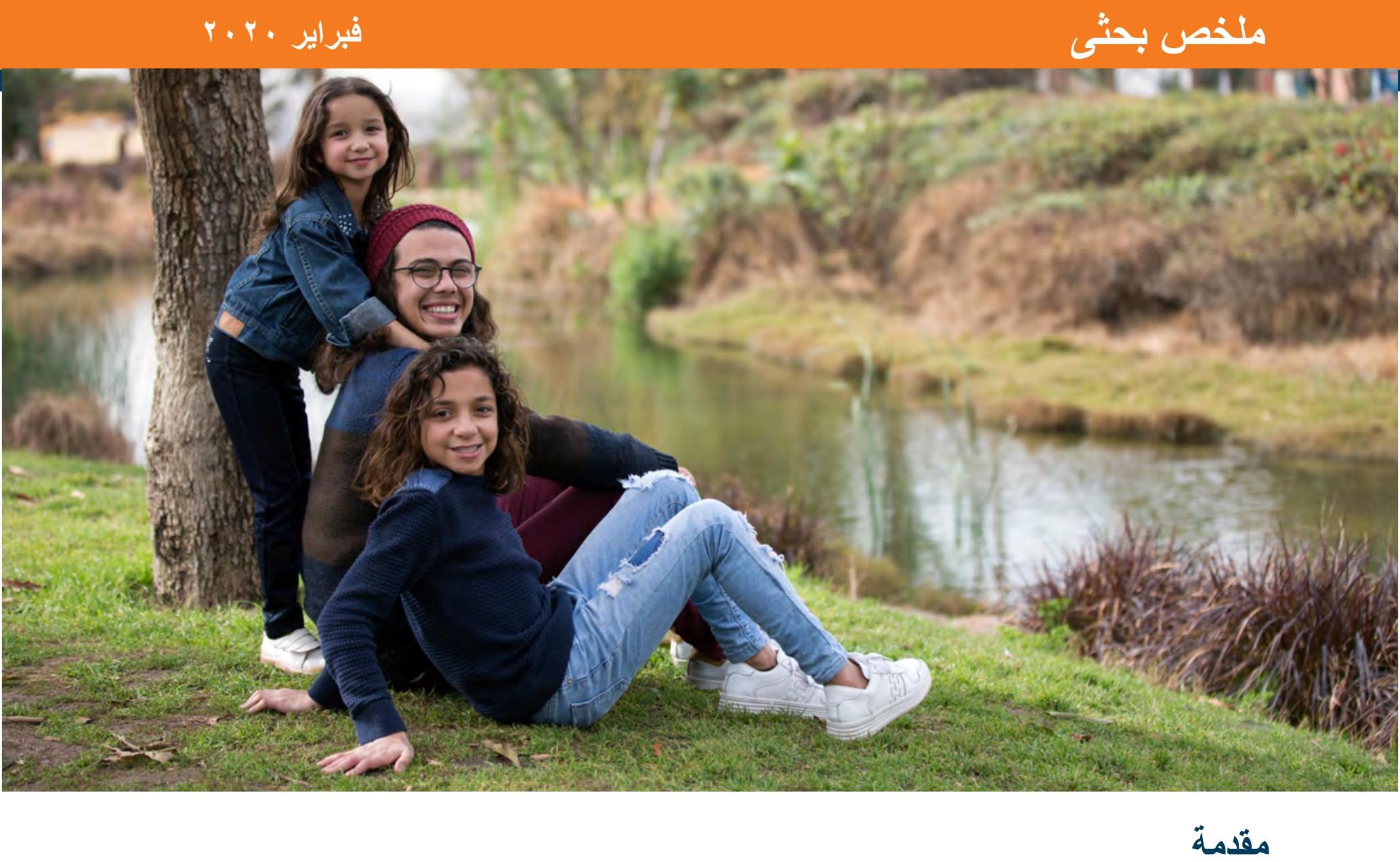

وبناءَ على ذلك قامت الدولة المصرية بوضع الإستر اتيجية القومية

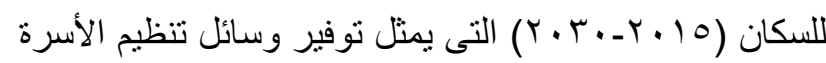
مكوناً أساسياً فيها، بالاضافة الى ، ونى رفع و وعي الثباب بتنظيم الأسرة ومز ايا الأسرة الصغيرة. وقد إنبثق من هذه الإستر اتيجية حزمة

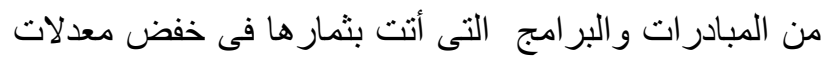
الإنجاب فى مصر ، فقد أظهرت در اسة حديثة (Sayed, 2019)

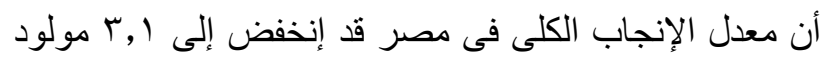

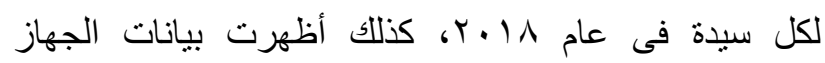

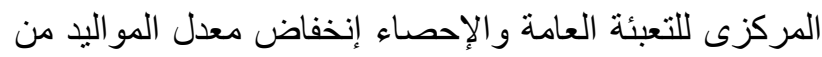

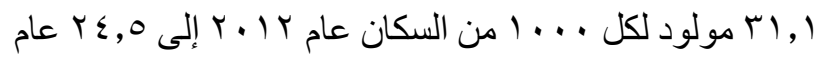

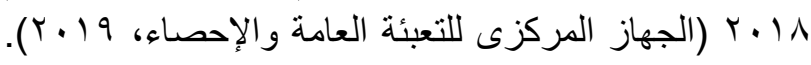

حقق برنامج تنظيم الأسرة فى مصر الكثير من النجاحات فى النى

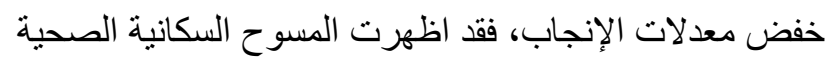

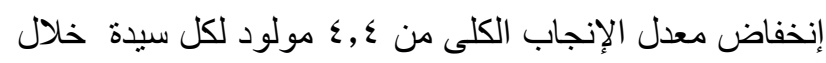

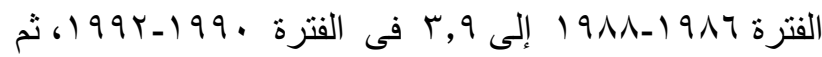

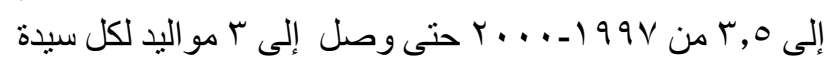

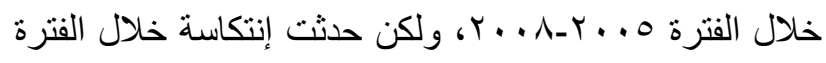

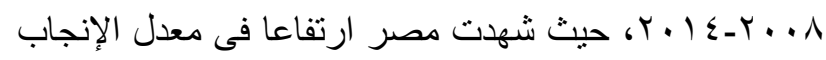

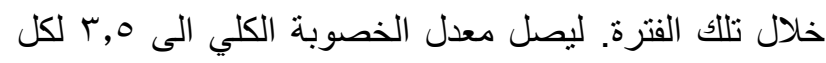

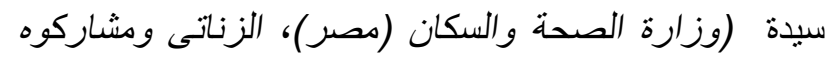
(مصر)، ومؤسسة ICF الدولية 2015). 
وبالرغم من هذا الإنخفاض إلا أن هناك ضرورة ملحة أهم الأتثائج

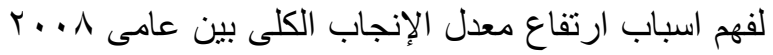

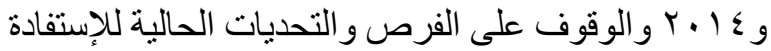

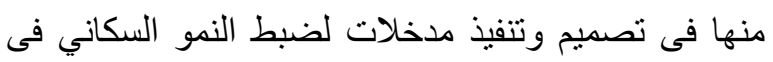
مصر ليكون منوازنآ مع معدلات النمو الأقتصادي.

كان أهم أسباب الزيادة فى معدل الخصوبة الكلي بين عامي

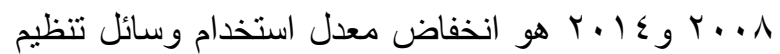

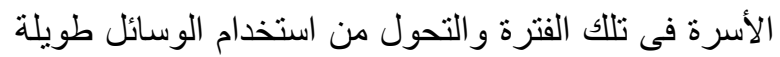

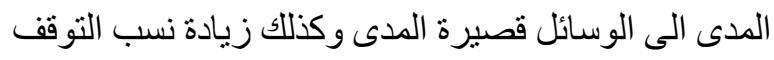

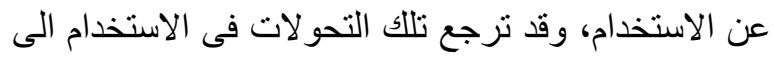

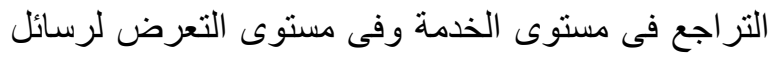

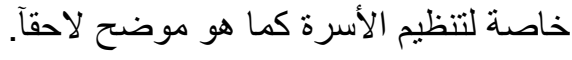

إنخفاض معدل استخدل/م وسائل تثطيم الأسرة

انخفض معدل إستخدام وسائل تنظيم الأسرة بين السيدات

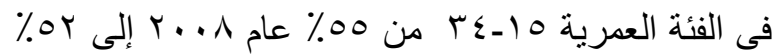

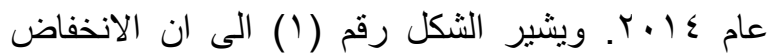

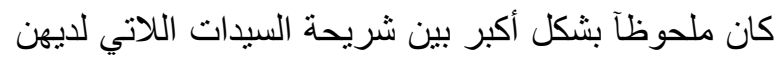

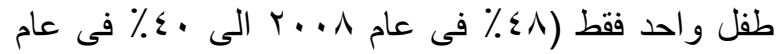

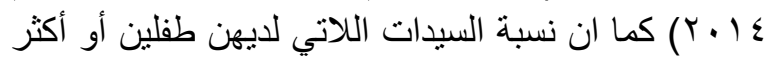

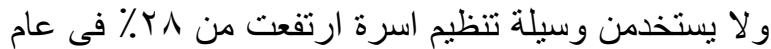

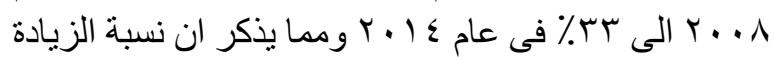
فى عدم الاستخدام كانت أكثر وضوحاً بين السيدات الناتي ينتمين للشريحة الاعلى فى الدخل (Yr\%) و السيدات اللاتي يقطن فى حضر الوجه القبلي (r؟\%).

ومن هذا المنطلق قام مجلس السكان الدولى بمصر وبدعم

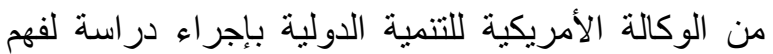

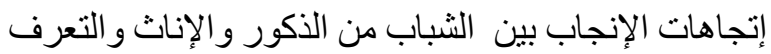
على أسباب الإرتفاع فى معدل الإنجاب الكلى و عدد الأطفال

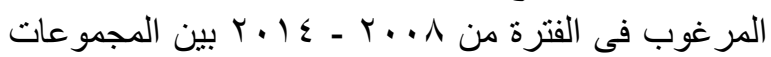

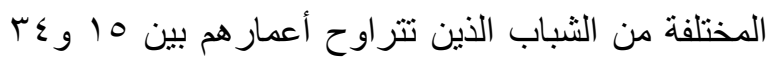

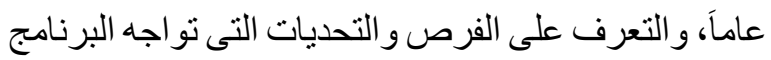
القومى لتنظيم الأسرة فى الوقت الر اهن.

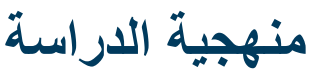

اعتمدت الدراسة على التحليلات الثانوية لبيانات المسح

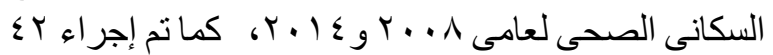
مناقثة بؤرية مع مجموعات من الثباب الأكور و الإناث

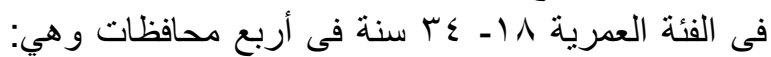

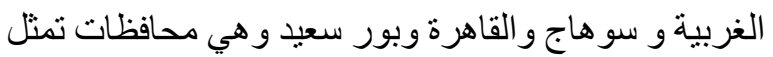
أنماطاً انجابية مختلفة ، وكذلك إجر اء 19 أمقابيلات متعدقة مع عدد (9 (1) من الخبراء و المسئولين فى مجالي السكان و الصحة الانجابية.

شكل رقم ا: النسبة المئوية للسيدات المتزوجات اللائي تتراوح اعمارهن بين ه 1 ــ ب عاماً ويستخدمن اي وسبية من

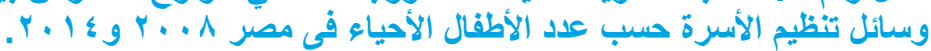

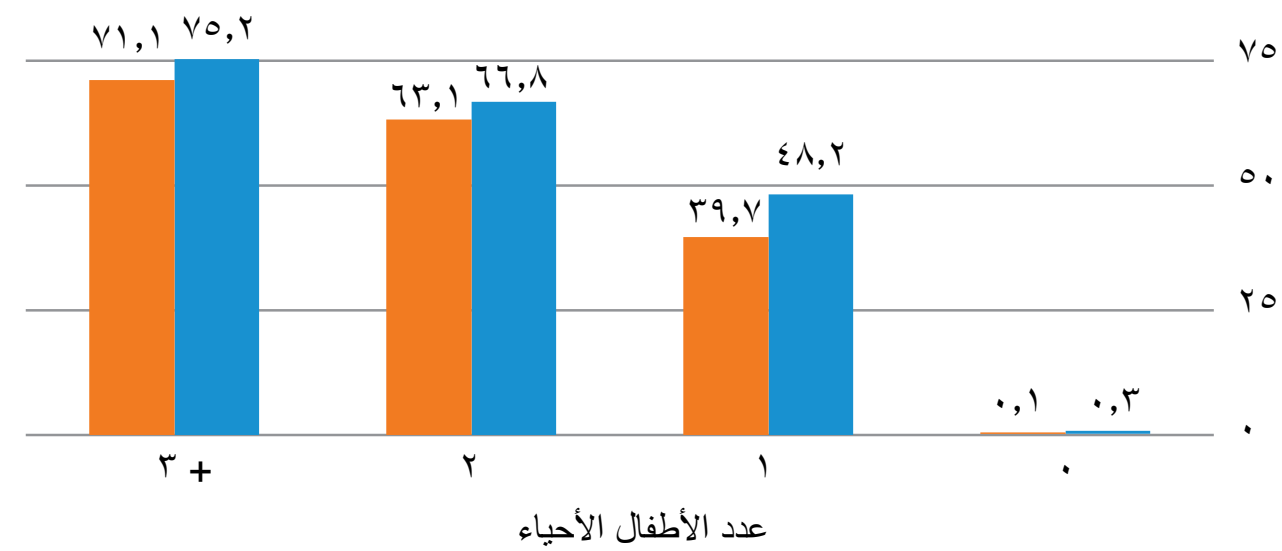

$r \cdot 1 \leqslant \quad r \cdot \lambda=$

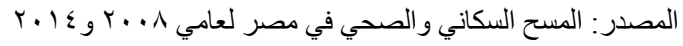




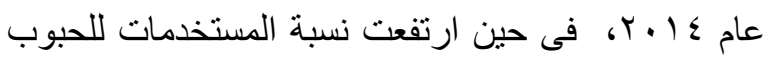

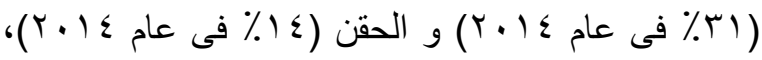

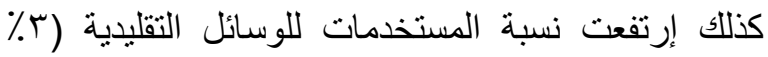

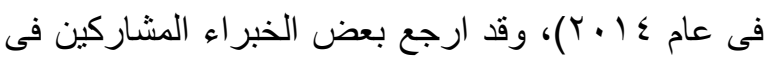

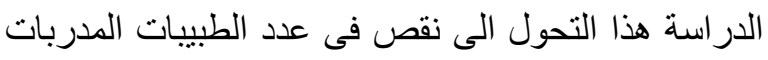

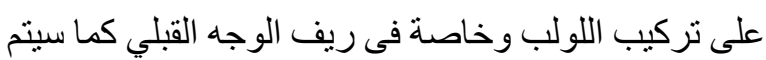
توضيحه لاحقآ.
التحول من استخدام الوسائل طويلة المدى إلى إلى

الوسائل قصبرة من المدي

بالرغم من أن اللولب مازال وسيلة تنظيم الأسرة الأكثراستخداماً فى مصر إلا أل أن نسبة السيدات في الفئة الفئة

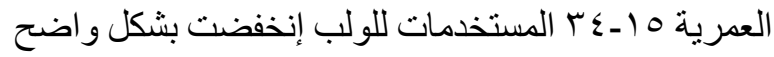

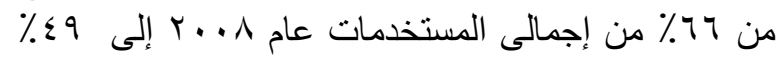

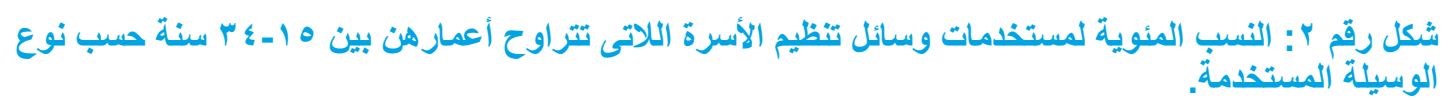

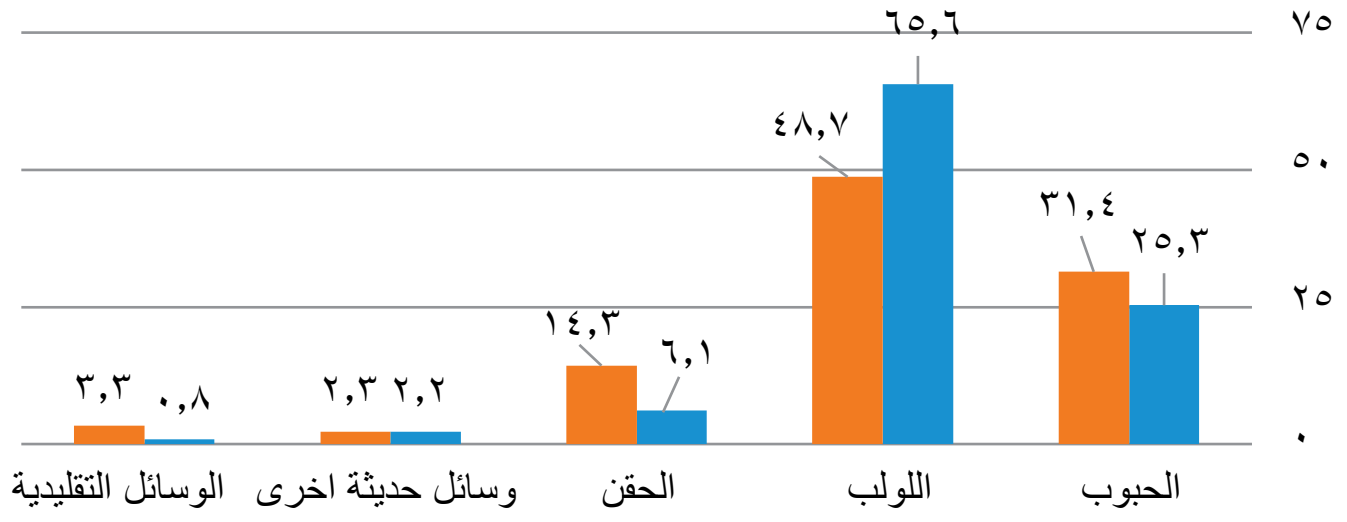

$r \cdot 1 \leqslant \square \quad r . . \Lambda \square$

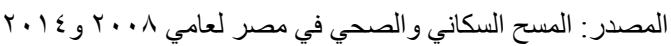

للمسح السكانى الصحى و حصلن على المعلومات الأساسية الخاصة بوسائل تنظيم الأسرة (وسائل تنظيم الأسرة

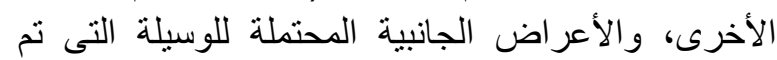

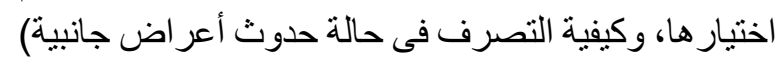

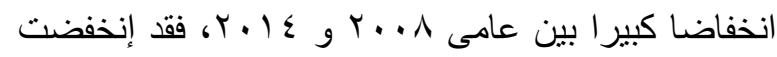

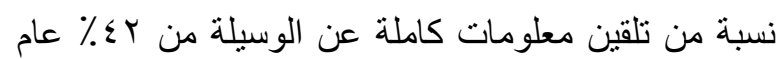

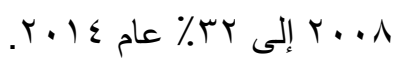

كان الإنخفاض فى تلقى مشورة عن وسائل تنظيم الأسرة

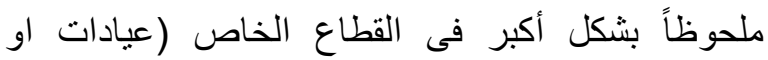

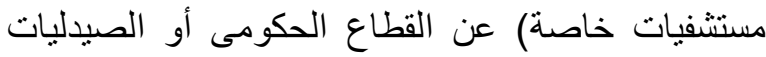

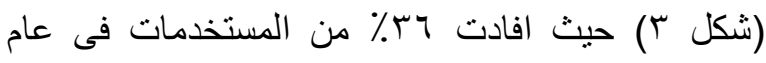

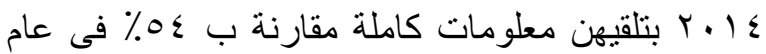

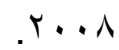

$$
\begin{aligned}
& \text { إرتفاع معدل التوقف عن إستخدام وسائل تنظيم } \\
& \text { الأسرة }
\end{aligned}
$$

ارتفع معدل التوقف عن إستخدام وسائل تنظيم الأسرة خلال السنة الأولى من الإستخدام بين السيدات في الفئة العمرية

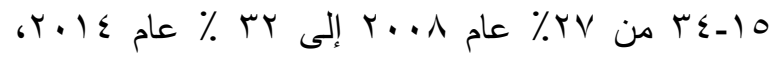

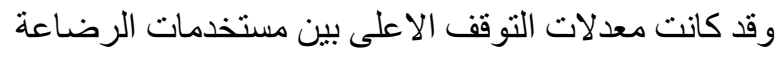

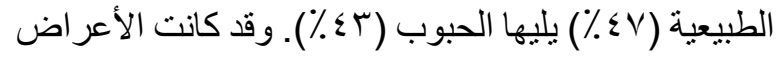

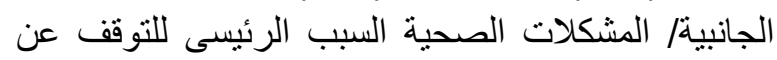

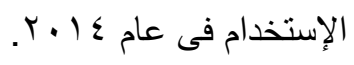

إنخفاض جودة المشورة الخاصة بوسائل تنظيم

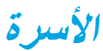

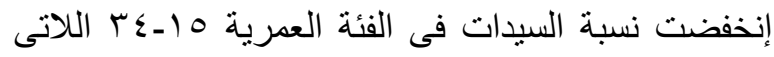

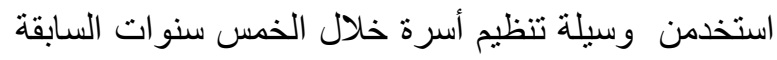




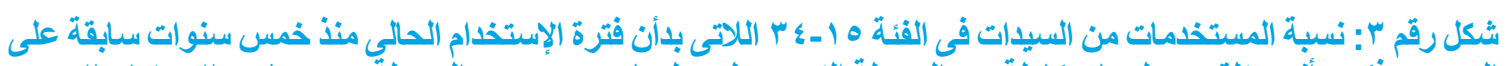

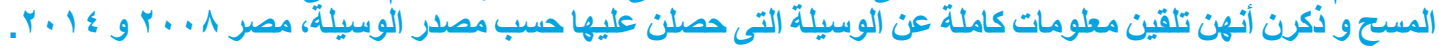

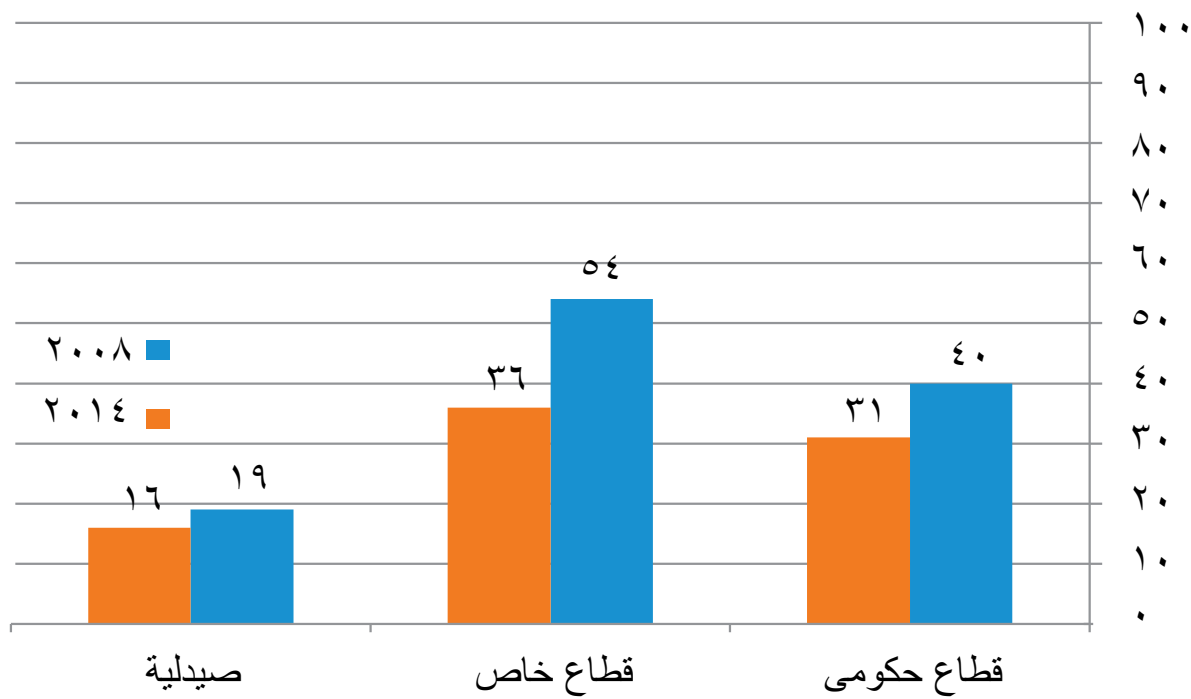

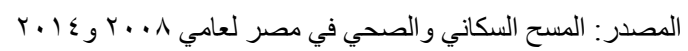

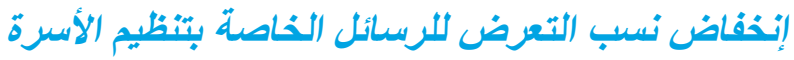

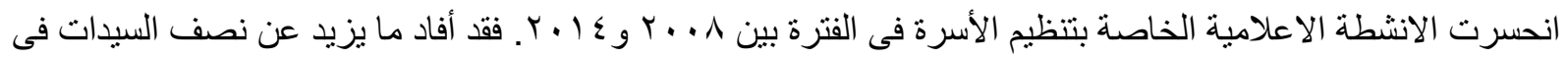

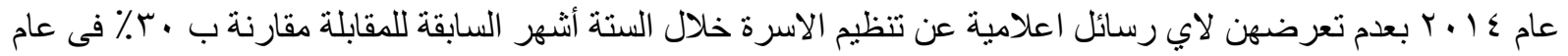

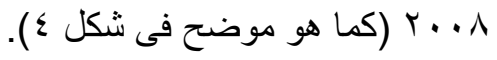

شكل رقم ؛ : نسب تعرض السيدات فى القئة العمرية ه 1 ــ ب لرسيائل إعلامية عن تنظيم الأسرة من مختلف قنوات الإعلام ، مصر

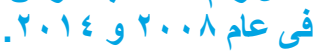

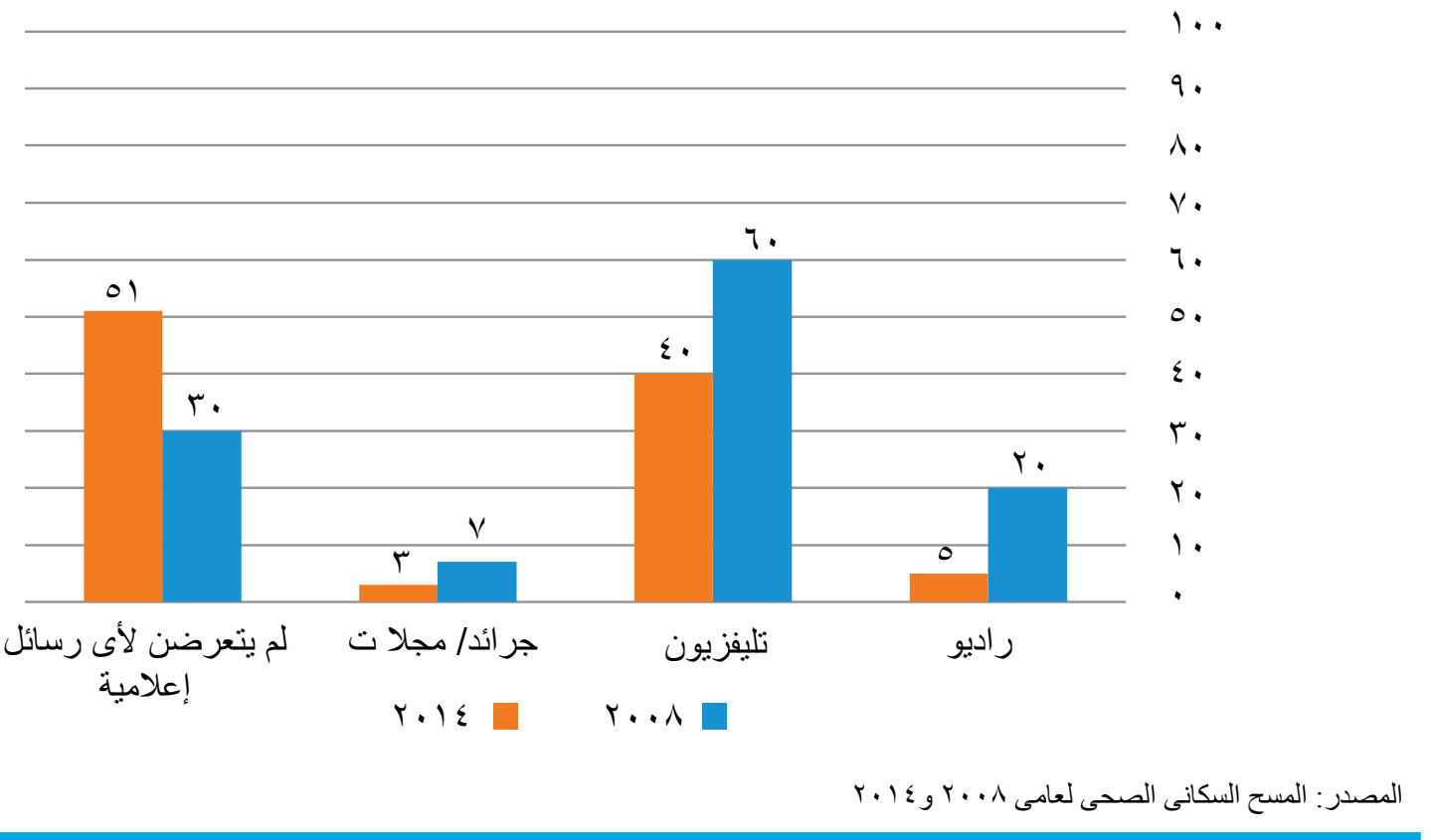


ازمان كان فيه بروتوكول تعاون بين وزارة الأوقاف

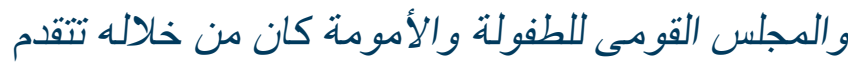
رسائل تنظبم الأسرة فى خطبة بوم الجمعة، كان مسدوح

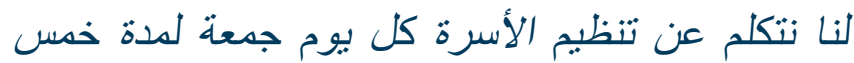

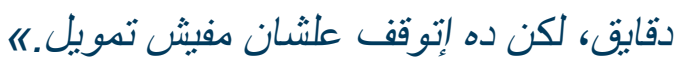

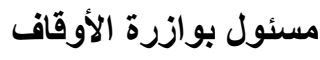

\section{انتشُار الفنوات الإعلامية الخاصة}

يعد زيادة عدد القنوات الأعلامية الخاصة مع ارتفاع تكلفة

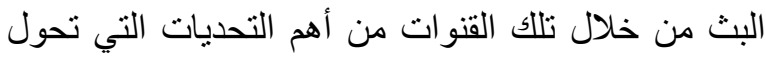

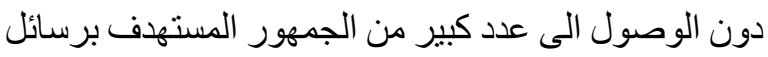
عن تنظيم الأسرة.

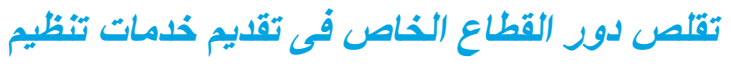

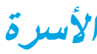

واجهت العديد من الجمعيات الأهلية فى الفترة من ^ ... ؟-

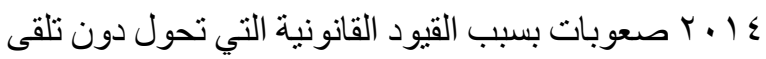

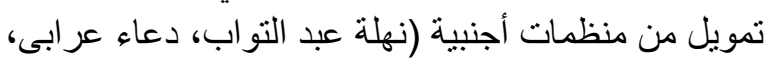

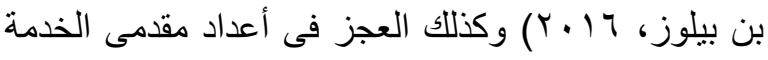

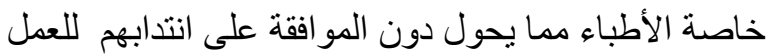

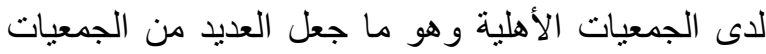

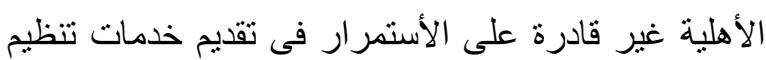

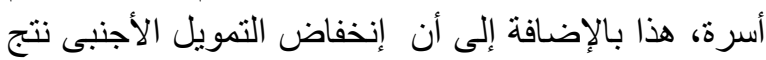

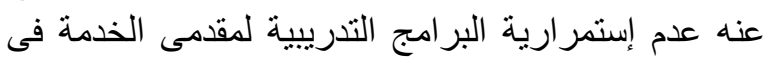

القطاع الخاص مما أدى إلى تر اجع فى مستوى الخدمة.

\section{المنظور الحالي للشباب عن الانجاب وثنظيم الأسرة}

اتت نتائج المناقثنات البؤرية مع الثباب منسقة مع البيانات

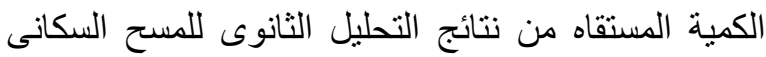

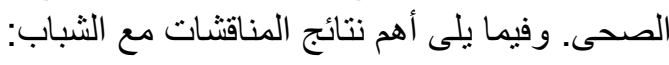

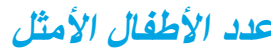

لا يعد إنجاب طفلين التفضيل السائد بين الثباب حاليا، فقد أفاد عدد من المشاركين فى القاهرة والغربية وبور سعيد النابل ان ثلاثة أطفال هو العدد الأمثل اذ أن أن وجود ثثلاثنة أطفال

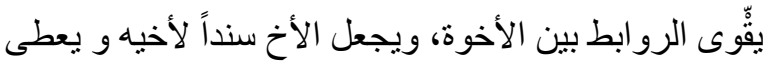

عوامل وظروف ساهمت في ارتفاع معدل

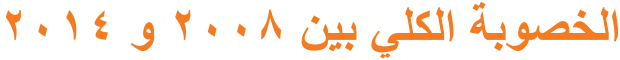

هناك العديد من الظروف السياسية والأقتصادية، وكذلك تلاك

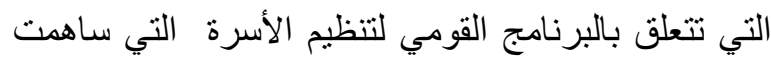

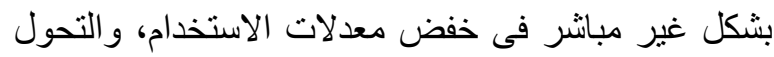
عن الوسائل طويلة المدى وزيادة معدلات التوقف عن الأن

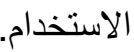

\section{التغير فى الظروف السبيسية والإقتصادية}

لقد كان للإضطر ابات الأمنية التى أعقبت ثورتي Oب يناير

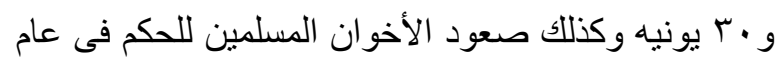

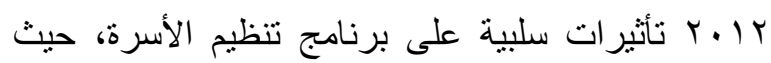

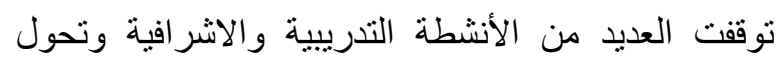
الخطاب السياسي من مشجع الى معارض لفكرة لفئن تنظيم

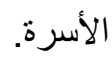

كما أن عدم استقرار الحالة الإقتصادية والأمنية أدى إلى الى

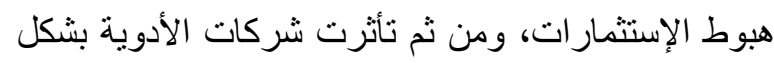

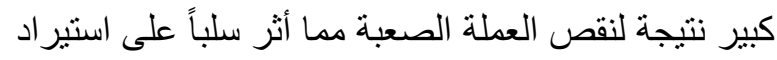
أنو اع من وسائل تنظيم الأسرة. وقد أفاد عدد من المسئولينين

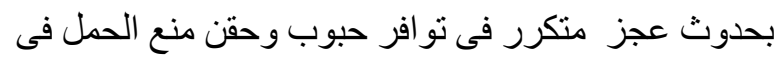
الصيدلبات خلال تلك الفترة.

ارفترة الإخوان المسلمبن كانت فترة صعبة، الناس كانت خايفة تتكلم عن تنظيم الأسرة، بعض الجمعين الإنيات الأهلية

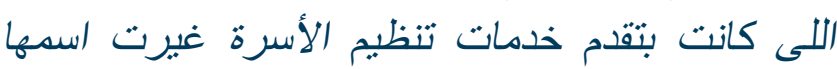

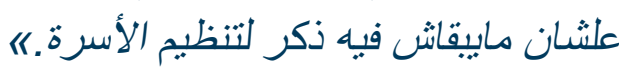

مسئول سابق بوزارة الصحة والاكسكان

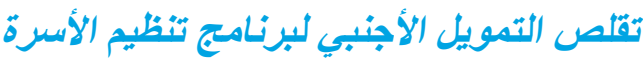

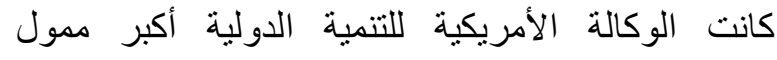

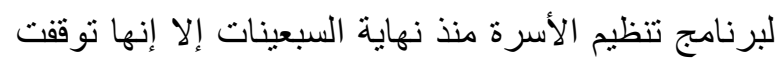

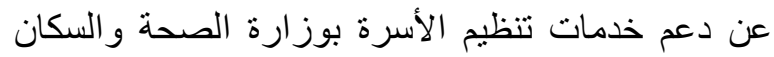

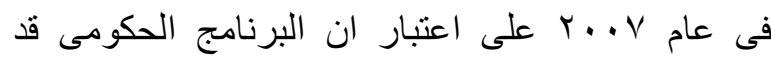

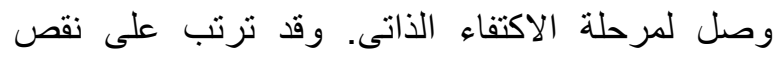

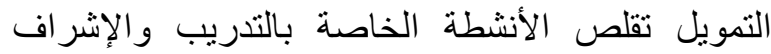

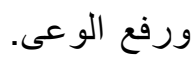




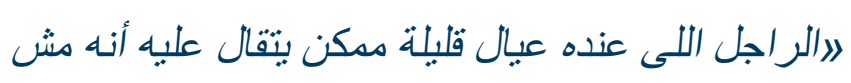

راجل علشان مش قادر يصرف على عيلة كبيرة. شاب من منطقة حضرية فى سوهاج

المباعدة بين الولاد/ت

معظم المشاركين أفادوا بأن فترة المباعدة المثلى هي ثنلاث

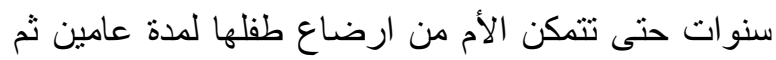

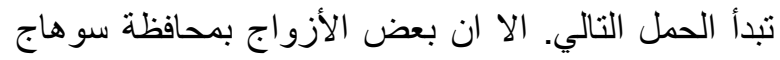
يفضلون فترات مباعدة أقصر من ثلاث سنو الات التهن حتى يتمكن الابوان من انجاب جميع اطفالهم فى مرحلة الثباب.

تفضيل انجاب الذكور

اتضح من خلال المناقثات البؤرية ان الازواج والزوجات

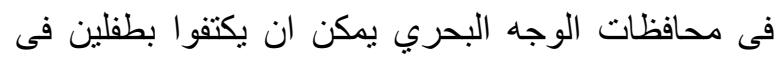

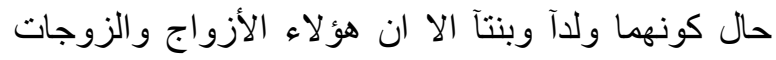

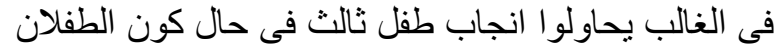

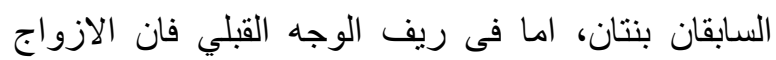

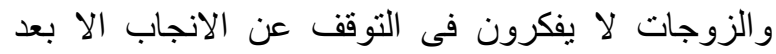

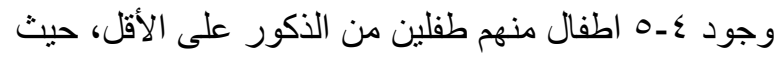

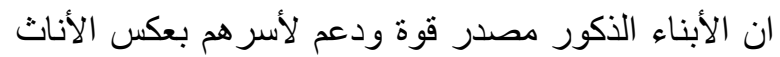
اللاتي يعتبرن عبئًا على الأبوين.

اإحنا هنا فى الصعبي بنتبع المثل اللى بيقول لالما

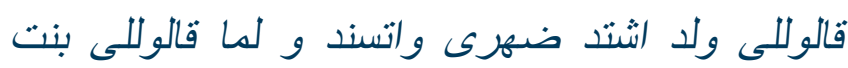

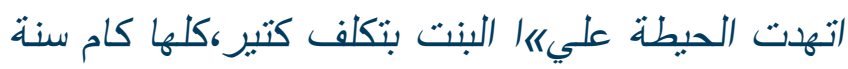

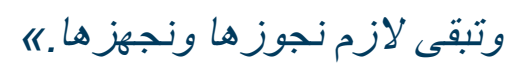

شاب من منطقة ريفية فى سوهاج عمره لـ بـ سنة متزوج

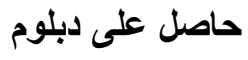

الوعي والاتجاهات حول تنظبم الأسرة

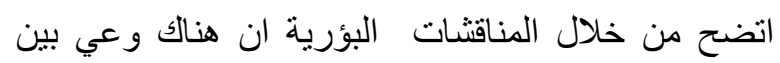

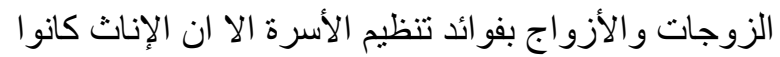

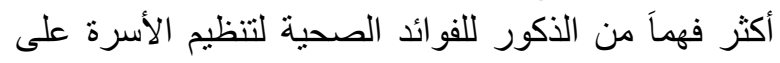
الأم و الطفل بينما ركز الذكور على الذئ الفورائد المادية فقط.

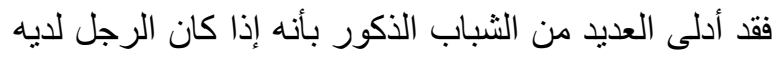

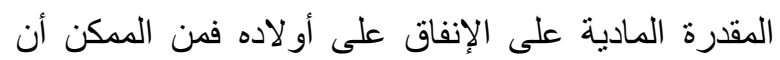
ينجب عدد الأطفال الذي يرغب الإنفاق فيه.
حيويه للأسرة. الا أنه نظر آ لصعوبة الظروف الإقتصادية

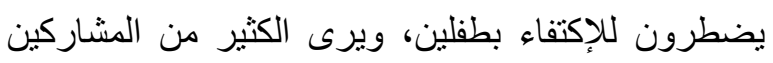

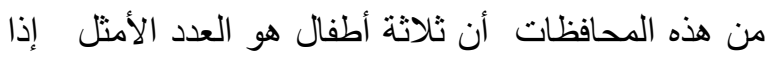

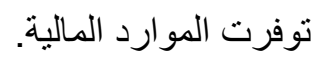

ا زمان كانت الحياة سهلة، وكل حاجة رخيصة فكانت الناس بتخلف أربع وخمس وست عيال لكن إحنا مانقدش رشاء

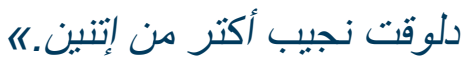

\section{سيدة متزوجة عمرها و ب سنة من القاهرة}

ارأنا كنت بنت واحدة فى الأسرة و أخويا كان ولد واحد، كل واحد فينا كان حاسس أنه لوحده، لكن لما بيقى فية الأبرة

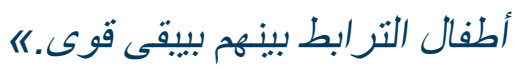

فتاة غير متزوجة خريجة جامعة من منطقة حضرية فى الغربية

الو الست ما تقدرش تجيب للك عدد العيال اللى أنت

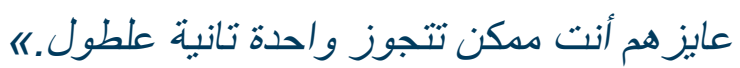

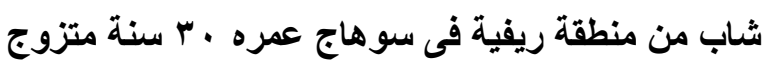
وحاصل على دبلوم

أما الثباب فى الوجه القبلي فيرون أن إنجاب عـــ أطفال

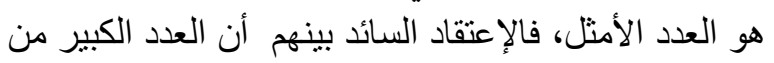

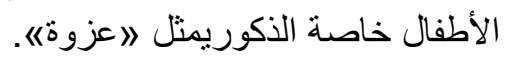

وقد أتضح ضغط الأهل والمجتمع المحيط له تأثير واضح

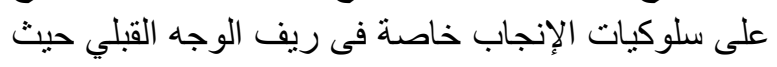

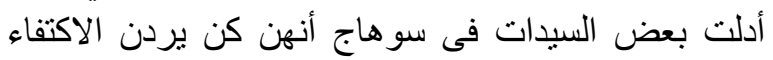

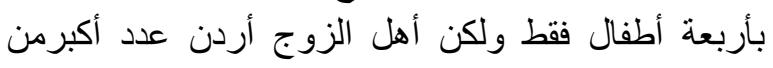
الأطفال فأضطررن للامنثال لمطالبهم.

الرأربعة كوبسين خصوصاً لما تربيهم كويس ويكون فيه بينهم مسافة كافية وما تفرقيش بينهم .... فى البلد عندنا أربعة كويسين، لكن الواحدة لازم تحترم حماها وحماتها،

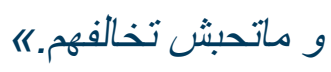

سيدة متزوجة من منطقة ريفية فى سوهاج 
تحت الجلد والو اقي الذكري او اقر اص منع الحمل لحالات

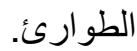

الا ان الإعتقاد الخاطئ بأن وسائل تتظيم الأسرة تؤثر على الجى الإنجاب فى المستقبل كان سائداً بين الثباب الذاعن الذين شاركوا

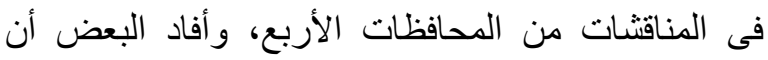
مقدمي الخدمة يحذرون من إستخدام وسائل تنظيم الأسرة قبل إنجاب الطفل الأول، و هنالك ايضاً مفاهيم خاطئة تتعلق التقات بفاعلية اللولب فى منع الحمل، أو ان الوسائل الهرمونية

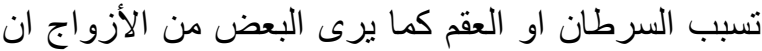

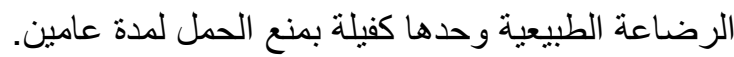

ارأنا روحت علثان أخد الحقن قالولى (فى الوحدة

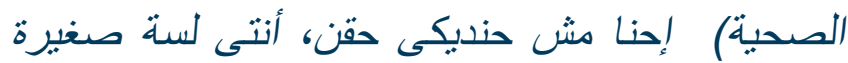

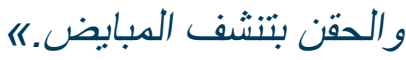

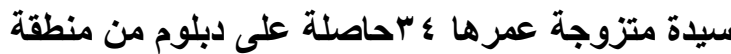
حضرية فى محافظة الغربية

الدكتور (طبيب خاص) قالى أن الحقن بتاعة التلات شهور مدنو عة فى أوربا لأنها بتسبب أورام سرطانية. سيدة متزوجه عمر ها 9 ب سنة حاصلة على تعليم جامعى من محافظة القاهرة

الكبسولات بتتحط تحت الجلد، وطول ما الكبسولات تحت الجلد بتسبب سرطان."

فتاة غير متزوجة، عمر ها ؟ ب سنة، خريجة جامعة، ومن بور سعيد

الحقن اللى بتتاخد كل ب شهور بتحفظ المبه فى الجسم

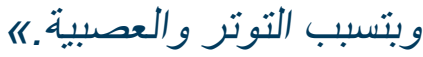

سيدة متزوجة من بور سعيد ، عمرها ب ب سنة خريجة جامعة

التجارب الشخصية الخاصة بإستخدام وسائل تنظيم الأسرة

أدلت العديد من المشاركات عن تعرضهن لأعر اض جانبية

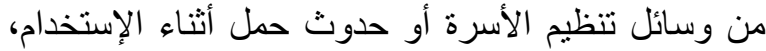

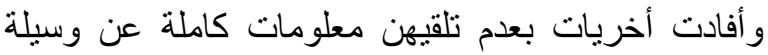

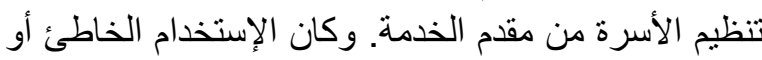

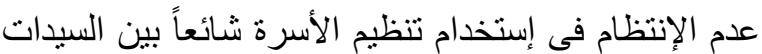

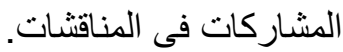

بالرغم من وجود إتجاه إيجابى بين الثباب نحو إستخدام

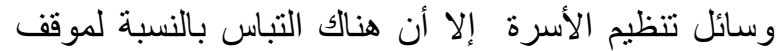

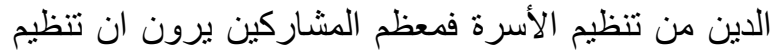

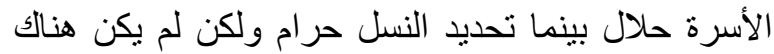

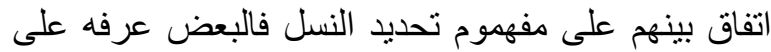

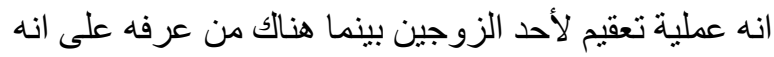

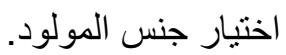

المفيش حاجة بتقول أن تنظبم الأسرة حرام، لكن تحدبي

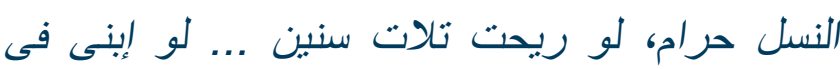

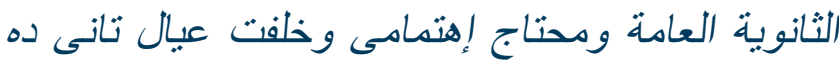

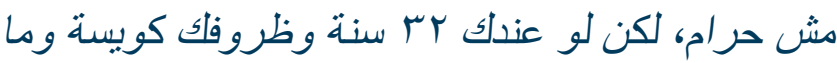
انتيش عايزة تحملى ده حر ام."

فتاة غير متزوجة من منطقة حضرية في سوهاجة دهاج عمرها

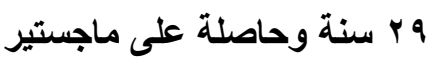

بالر غم من أن نظرة الشباب المشاركين في المناقتشات كانت

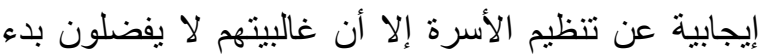
إستخدام وسائل تنظيم الأسرة قبل إنجاب الطفل الأن الأول، بينما

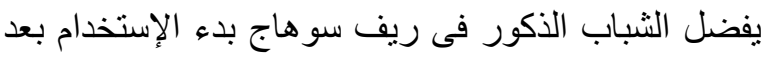
إنجاب الطفل الثنانى حتى يتحقق الزوجان من قدرتهم على

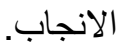

ارالأفضل استخدام وسبلة تنظبم الأسرة بعد العبل التانى

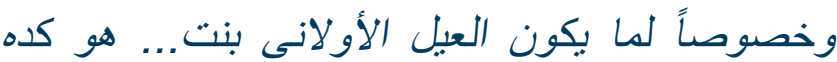

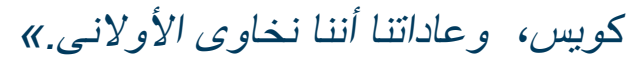
سيدة متزوجة غير متعلمة عمرها و ب سنة من منطقة ريفية في سوهاج

ارأعرف مدرسة إتجوزت وهى فى الجامعة، خدت الحبوب علثان تأجل الحمل لغاية ما تخلص تعليمها، وبعد ما خلصت حاولت تحمل لكن ما حصلث و الدكتور

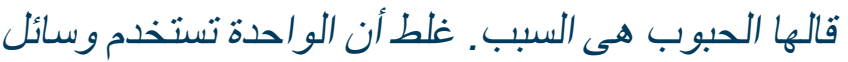

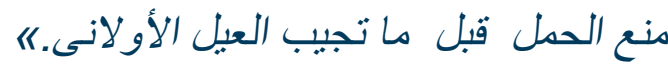
فتاة غير متزوجة من منطقة حضرية فى الغربية الابل

\section{المعرفة بوسائل تنظيم الأسرة}

معظم المشاركين افادو ا بمعرفتهم بالحبوب و اللولب و الحقن

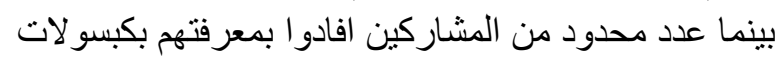


زيادة التمويل الحكومى والأجنبى المخصص لتنظيم

نجحت الحكومة المصرية فى تغطية تكلفة وسائل تنظيم

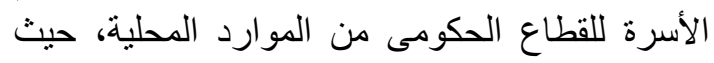

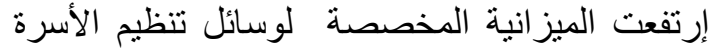

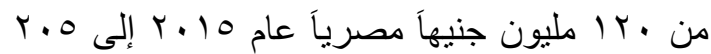
مليون جنيهاً مصرياً عام 1 1 • Y وذللك لتغطية الزيادة فى اسعار الوسائل الناتجة عن انخفاض فيمة الجنيه

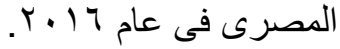
استأفت الوكالة الأمريكية للتنمية الدولية (USAID) دعمها للبرنامج المصرى لتنظيم الأسرة من خلال

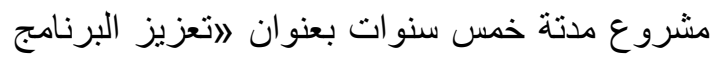

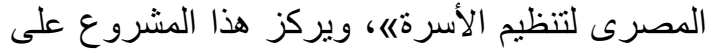

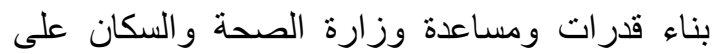
اتخاذ قرارات وتبني سياسات مبنية على الادلة العلمية. هناك منظمات دولية أخرى مثل الإتحاد الأروبى،

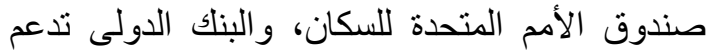
برنامج تنظيم الأسرة من خلال توفير الداعم اللازم اللان

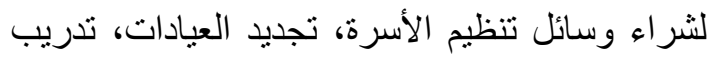
مقدمى الخدمة و أنثطة لرفع الوعى من خلال الر ائدات

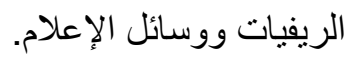

الإصلاحات القانونية المتوقعة التى بيكن أن تسهح

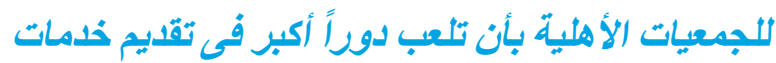

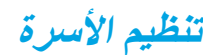

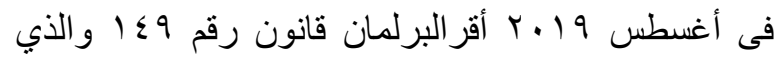

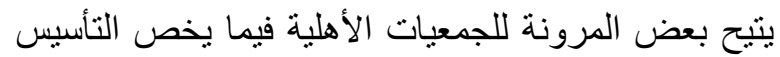

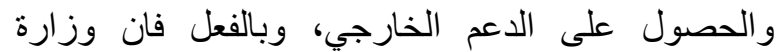

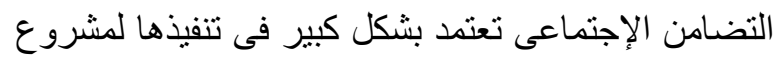
》إتنين كفايةه الممول من صندوق الأمم المتحدة للسكان

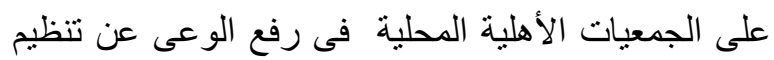
الأسرة وتقديم خدمات تنظيم الأسرة.

\section{زيادة إستخدام الشباب لوسائل الإتصال الحديثة}

شهدت مصر إرتفاعاً غير مسبوق فى إستخدام الانترنت التهات

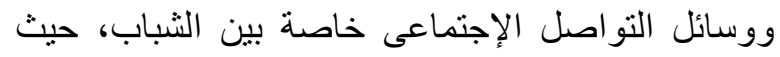

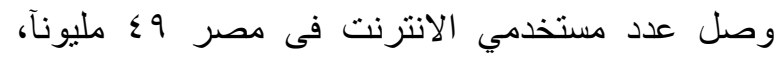

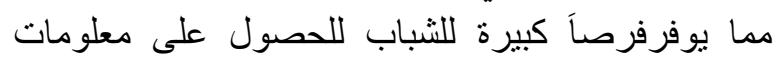
عن تتظيم الأسرة والصحة الإنجابية من مصادر متعددة

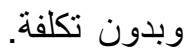

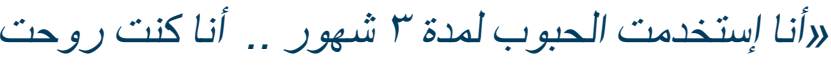

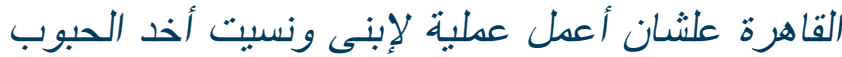
معايا، وحصل لى نزيف وأنا فى القاهرة، و لما رجعت من سوهاج استخدمت الحبوب وأنا عندى النزيف، وبعا وبعدين روحت للاكتور وهو قاللى أنى أغبر الحبوب واستخدم

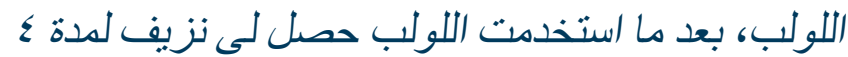

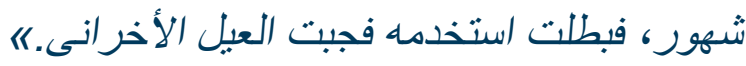
سيدة عمرها • ب سنة من منطقة حضرية فى محافظة سوهاج

ارأنا إستخدمت اللولب و الحبوب، استخدمت اللولب لمدة أربع أو خمس سنين لكن سبب لى نزيف شديب وصداع

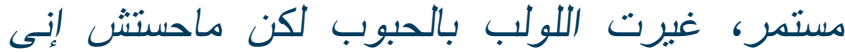
مرتاحة برضها، الحبوب خليت جسمى ورم." سيدة عمرها اس سنة من منطقة حضرية فى محافظة الغربية

الأقرص والتحديات التى ثواجه برنامج تنظيم اللاعم الكبير من القيادة السباسبية والحكومة المصرية

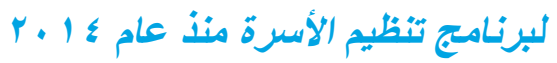
• لأول مرة فى تاريخ الدولة الدصرية بلزم الدستور

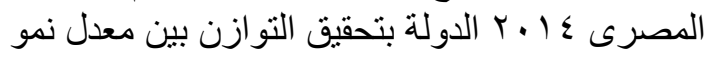

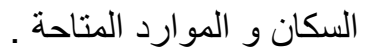

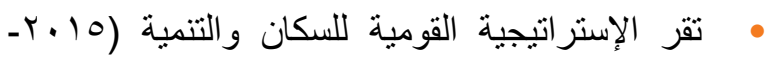

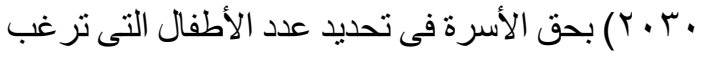

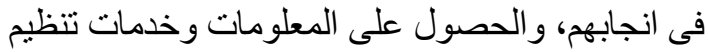
أسرة التى تساعد الأسرة على تحقيق العدد المرغوب

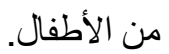

الرئيس السيسى داعم قوى للقضية السكانية فهو دائماً يحث على بذل الجهود للحد من الزيادة السكانية، فقى للعى

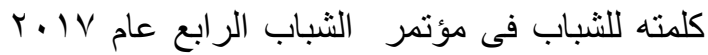
وصف النمو السكانى السريع بأنه إحد أهم التحديات التى تو اجه الدولة المصرية.

الكبر خطرين يواجهان مصر فى تاريخها الارهاب و الزيادة السكانية.. هذا التحدى (الندو السكانى) بيقلل فئل فئل

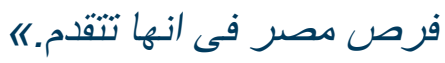

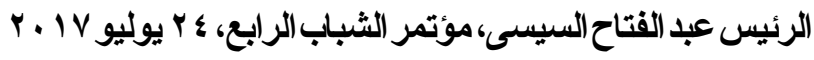




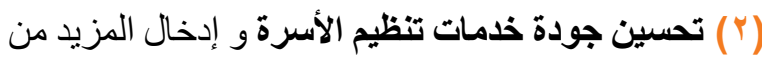

الوسائل طو يلة المدى فى القطاعين الحكومي و الخاص،

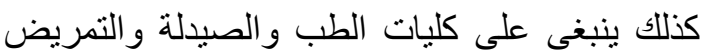
تضمين معلومات مفصلة وتدريبات عملية عن وسائل تنظيم الأسرة في مناهج الطلاب للتأكد من أن الخرجين

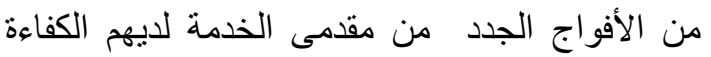
و المعرفة اللازمة لتقديم خدمة ذات جودة عالية.

(ب) تضمين مشورة عن تنظيم الأسرة مع الخدمات الصحية الأخرى: ينبغى الإستفادة من كل الخدمات

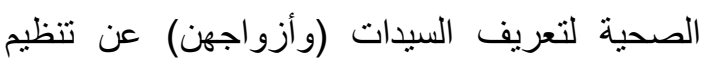

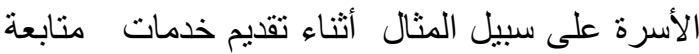

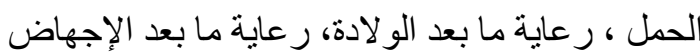

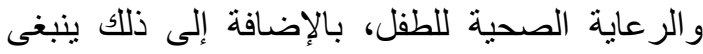

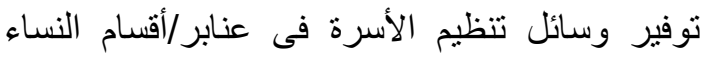

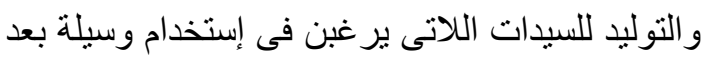
الو لادة أو الإجهاض مباشرةً.

(أ) تعزيز دور القطاع الخاص في تقديم خدمات تنظيم الأسرة: ينبغى على الدولة المصرية مساعدة الجمعيات

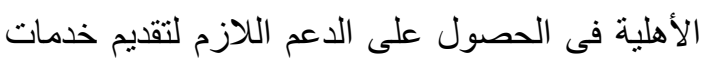

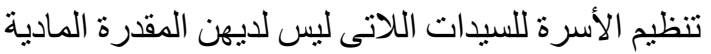

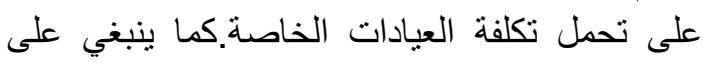

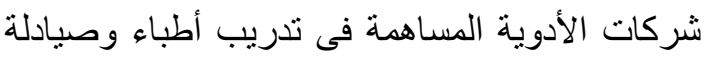

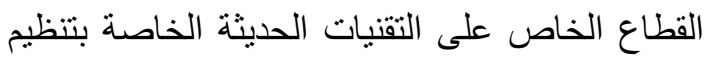
الأسرة مما سوف يسهم فى زيادة المبيعات وزيادة الربح لتلك الثركات.

(0) تعزيز الشراكات بين القطاعين الحكومى والخاص: ينبغى على الجهات التشريعية إعادة النظر فى القو القو انين

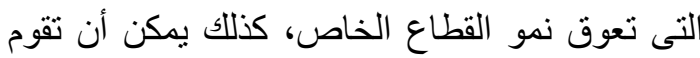

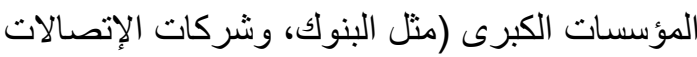

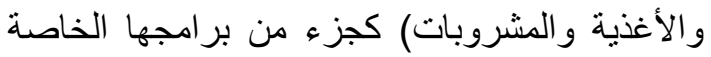

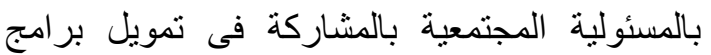

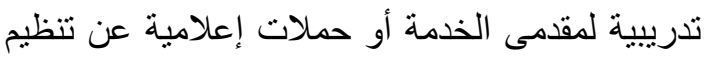
الأسرة أو المساهمة فى تجهيز وحدات تابعة لوزارة الكارة

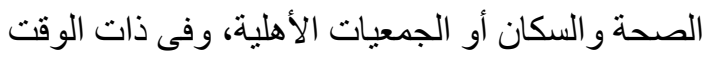

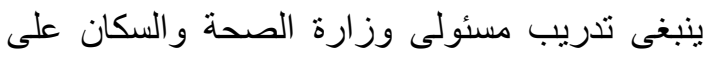
كيفية الإستفادة من موارد القطاع الخاص.

اجراء المزيد من البحوث: ينبغي على الجهات البحثية

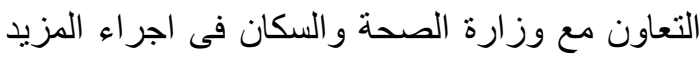

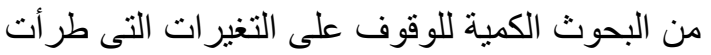

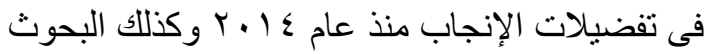
الكيفية للوصول الى فهم أعمق لتفضيلات الإنجاب و السلوك الإنجابى للزورجين لتحديد إلى أى مدى يتخذ لإنى

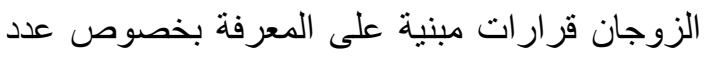

العجز فى الأطباء المدربين فى وحدات الرعاية الصحية

أفاد المشاركون فى المقابلات من الخبراء والمسئولين

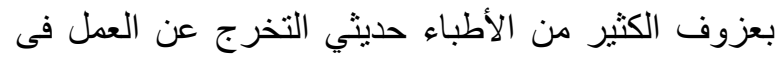

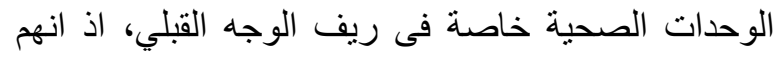

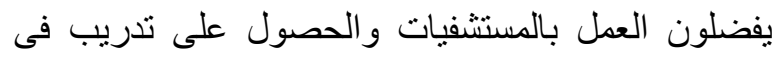
تخصصات مثل النساء و التوليد والجر احة العامة، وبالتالي

تحقيق مكاسب مالية أعلى عند فتحهم عياداتهم الخاصة.

اربتهاع أسعار وسائل تنظيم الأسرة بإلقطاع الخاص

ادت الاصلاحات الاقتصادية الأخيرة مثال تعويم الجنيه

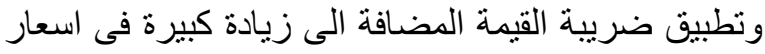

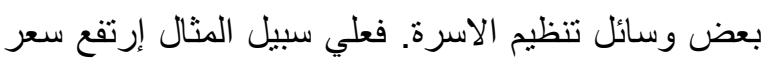

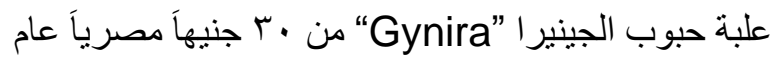

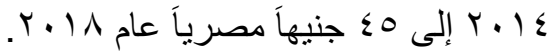

\section{الخلاصة و التوصيات}

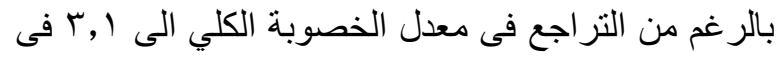

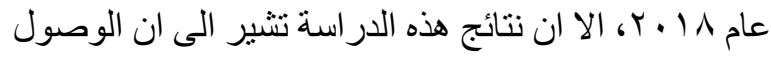

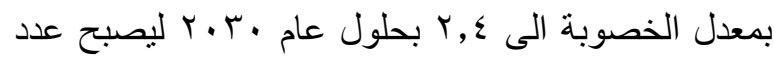

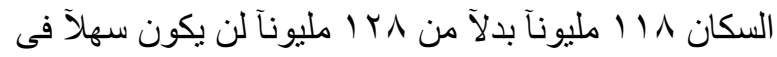

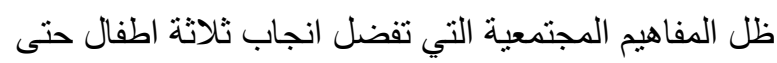

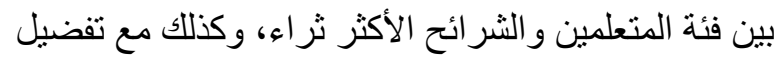

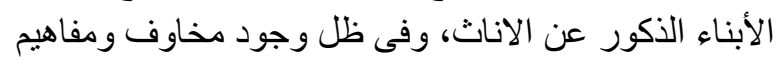
خاطئة بخصوص وسائل تنظيم الأسرة.

لذا، ينبغي على البرنامج القومي لتنظيم الأسرة تبني استراتيجية شاملة ومستدامة لضمان استمرارية وفاعلية التئية

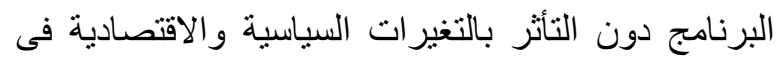

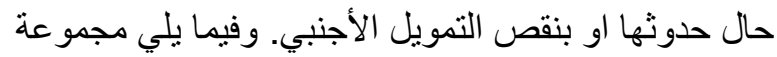
من التوصيات و المقترحات.

(1) رفع الوعى عن تنظيم الأسرة بين الفئات المختلفة

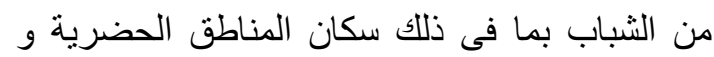

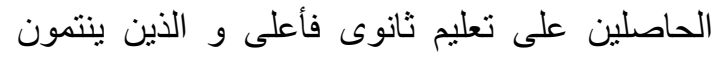

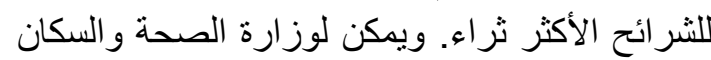

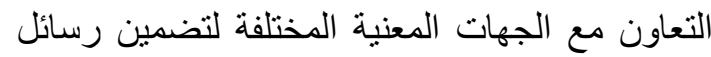

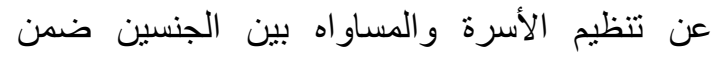

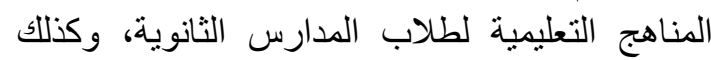

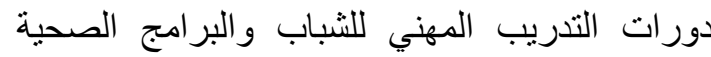

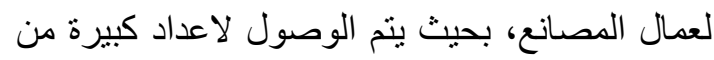

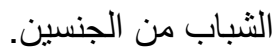




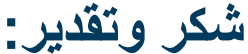

نتقلم بخالص الثكر لكل من قدم الدعم اللازم لاجراء

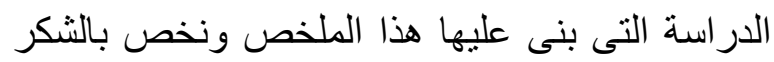

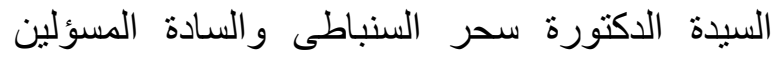
بقطاع السكان وتنظيم الأسرة بوزارة الصحة و السكان

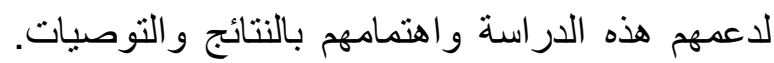

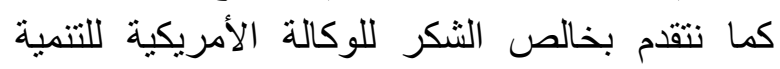

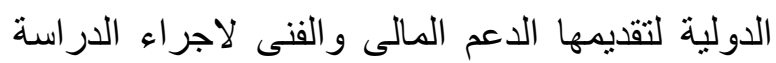
و اعداد هذا الملخص.

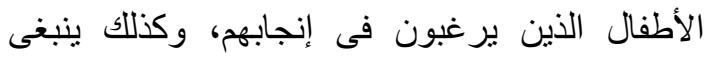

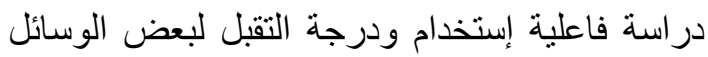

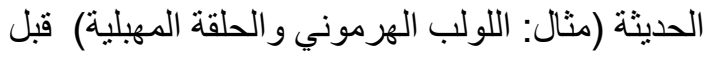

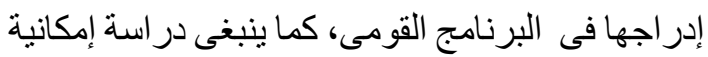
الإستفادة من التقنيات الحديثة للإتصال مثال: استخدام

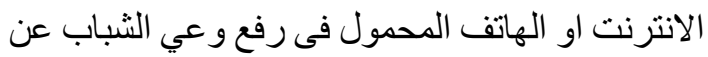

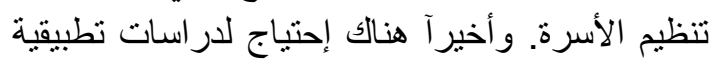

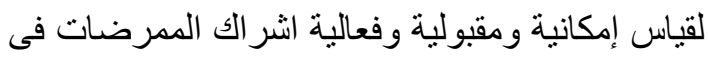

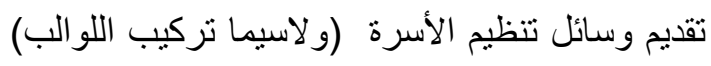

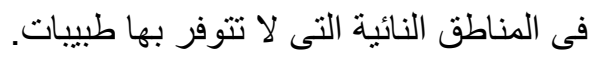

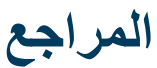

\section{المراجع باللغة الانجليزية}

EISayed, Hussein A. (2019) "Trends of Fertility Levels in Egypt in Recent Years", Ministry of Planning, Monitoring and Administrative Reform and UNFPA

\section{المر اجع بالمأة العربية}

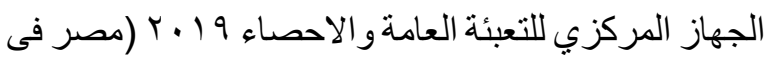
ارقام) القاهرة، الجهاز المركزي للتعبئة العزئة العامة والاحصـاء $r \cdot 1 \leq-r \ldots 1$

وزارة الصحة والسكان (مصر)، الزناتى ومشاركوه

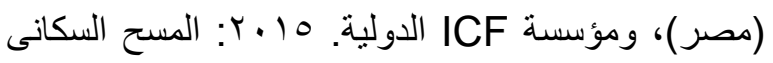

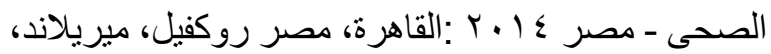
الواليات المتحدة الأمريكية، وزبرة وزارة الصحة وركة والسكان ومؤسسة الئ ICF.

فاطمة الزناتي و آن واى. 9. . . r. المسح السكاني الصحة

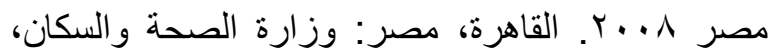
الزناتي ومشاركوه، وشركة ماكرو الدولية.

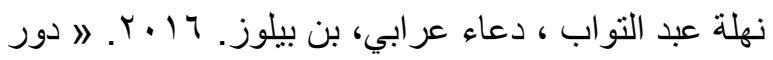

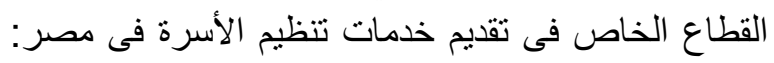

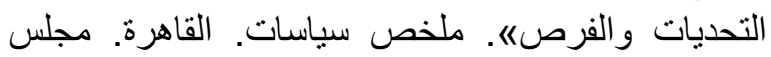

السكان الدولي The Evidence Project. 

صورة الغلاف: ابتكار (شاتر ستوك Shutterstock)

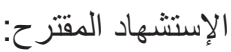

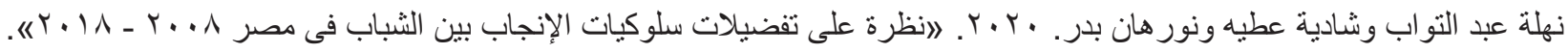
ملخص بحثى. القاهرة، مصر : مجلس السكان الدولى

تم استخلاص هذا الملخص من التقرير التالى:

Abdel-Tawab, Nahla, Shadia Attia, Nourhan Bader, Rania Roushdy, Shatha El-Nakib and Doaa Oraby. 2020. "Fertility Preferences and Behaviors Among Younger Cohorts in Egypt: Recent Trends, Correlates, and Prospects for Change," Research Report. Washington, DC: Population Council, The Evidence Project.

ثنفة هذا المشروع بدعم من الوكاله الأمريكية للتنمية الدولية، (USAID) وفتا لأنتاقية التعاون رقم AID.OAA.A.13-00087

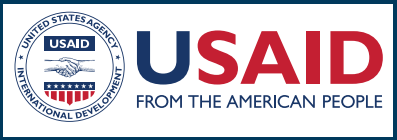

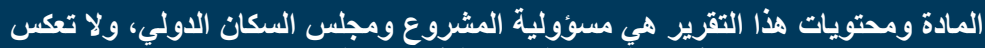

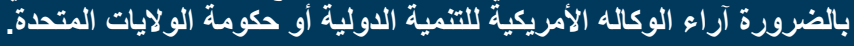

يستخدم مشروع Evidence منهرج البحوث التطبيقية لإستباط

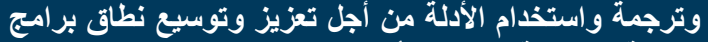

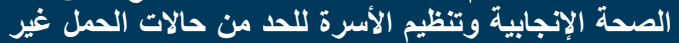
المخطط له حول العالم. ويرأس مشروع Evidence مجلس السكان الدولي.

\section{THE EVIDENCE PROJECT}

$$
\begin{aligned}
& \text { مجلس السكان الدولى } \\
& \text { r ا شار ع النهخة - المعادى الدولى } \\
& \text { صندوق بريد } 17
\end{aligned}
$$

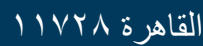

$$
\begin{aligned}
& \text { هاتف: rTONTIVY }
\end{aligned}
$$

evidenceproject@popcouncil.org 